\title{
Crescimento e qualidade de mudas de pinhão-manso produzidas em ambiente protegido ${ }^{1}$
}

\author{
Janaina Paulino², Marcos V. Folegatti2 ${ }^{2}$ D anilton L. Flumignan², Cornélio A. Zolin², \\ Cícero R. A. Barboza Júnior ${ }^{2} \&$ Sônia M. de S. Piedade ${ }^{2}$
}

\begin{abstract}
RESUMO
Devido ao recente Programa de Produção de Biocombustíveis do Brasil, o interesse comercial tem crescido em relação à produção de pinhão-manso (Jatropha curcas L.). Informações sobre esta cultura ainda são escassas, o que remete a necessidade de mais pesquisas que possam estabelecer condições de adaptabilidade desta cultura em diferentes condições. N este contexto, realizou-se um experimento para estudar o crescimento e a qualidade das mudas de pinhão-manso, produzidas em ambiente protegido; as mudas foram monitoradas até o momento de serem transplantadas para o campo. Foi analisada a influência dos tipos e volumes de recipientes, juntamente com diferentes substratos e formas de adubação; 0 consumo de água também foi analisado durante 0 experimento. De acordo com os resultados, as melhores taxas de crescimento e qualidade de mudas até a condição de transplantio, foram obtidas com a combinação do substrato comercial, maior tubete e adubo de liberação lenta.
\end{abstract}

Palavras-chave: cultivo em ambiente protegido, recipiente, substrato, Jatropha curcas L.

\section{Growth and quality of physic nut seedlings produced in greenhouse}

\begin{abstract}
There has been an increasing interest in the commercial production of physic nut (Jatropha curcas L.) due to the recent Brazilian Program of Biofuel Production. Information on this crop is still scarce and more research is necessary to set the grounds of crop adaptability in different local conditions. An experiment was set up on this issue under greenhouse environment. Growth and quality of physic nut seedlings was monitored up to transplanting time. The influence of types and volumes of seedling containers was analysed along with different substrates and fertilization strategies. The water use was also detailed in the trial. Results showed the best achievements of grow th rate and seedling quality, at appropriate transplanting time, were reached from the combination of the commercial substrate, largest containers and fertilizers of slow nutrient liberation.
\end{abstract}

Key words: protected environmental cultivation, container, substrate, Jatropha curcas L.

1 Parte da Dissertação de Mestrado do primeiro autor

2 ESALQ/U SP, Av. Pádua Dias 11, Agronomia, CEP 13418-900, Piracicaba, SP. Fone: (19) 3447-8553. E-mail: jpaulino@esalq.usp.br; mvfolega@esalq.usp.br; flumigna@esalq.usp.br; cazolin@esalq.usp.br; crabjuni@esalq.usp.br; soniamsp@esalq.usp.br 


\section{INTRODUÇÃO}

O pinhão-manso pertence à família das Euforbiáceas, a mesma da mamona e da mandioca. É um arbusto grande, de crescimento rápido, cuja altura normal é de dois a três metros, mas pode alcançar até cinco metros em condições especiais (Cortesão, 1956). Atualmente, o pinhão-manso é encontrado em quase todas as regiões intertropicais, ocorrendo na América Central, China, Índia, Filipinas e Timor Leste, até as zonas temperadas, porém em menor proporção (Heller, 1996).

No Brasil, o interesse na produção do pinhão-manso surgiu com a implantação do Plano Nacional de Produção de Biodiesel. Andréo-Souza et al. (2010) e Nery et al. (2009), informam que esta oleaginosa é considerada uma cultura potencial para atender a este programa, pois possui potencial de rendimento de grãos e óleo e, em sua fase inicial, permite o cultivo em consórcio com outras culturas de interesse econômico e alimentar. No entanto, os plantios comerciais de pinhão-manso no Brasil ainda estão em fase inicial de implantação e domesticação de espécies; espera-se que a cultura deixe de ser um potencial e passe a ser efetivamente uma matéria-prima para o mercado de biodiesel (Andréo-Souza et al., 2010).

Apesar da carência de informações técnicas básicas, a cultura vem sendo implantada e difundida em diferentes regiões do País e do mundo. Acthen et al. (2009) alertam ainda que é preciso ter precaução quanto à exploração desenfreada, pois isto poderá ser um obstáculo na obtenção do real potencial da cultura, haja vista que a ciência precisa ser aplicada em tempo apropriado.

As informações disponibilizadas na literatura, desde os requerimentos climáticos até as características da planta, são muito divergentes, ressaltando a importância do investimento em pesquisas com a cultura em todos os processos de produção (Sunil et al., 2008; Nery et al., 2009; Laviola \& Dias, 2008; Andréo-Souza et al., 2010).

O método clássico para análise de crescimento, citado por Silva et al. (2000), que nada mais é do que a estimativa dos valores médios das variações dos dados de crescimento em intervalos de tempo fixados por duas amostras sucessivas ao longo do ciclo, tem sido bastante utilizado para a investigação do efeito de fenômenos ocorridos, desde as influências ecológicas naturais até efeitos de tratamentos aplicados sobre o crescimento de diversas culturas. Em seu estudo, Cardoso et al. (2006) evidenciaram que o uso da análise não destrutiva é um ferramenta útil e eficiente na avaliação de cultivares, podendo esta análise ser mais completa, quando realizadas também as taxas de crescimento.

Para a produção de mudas de pinhão-manso o sistema mais recomendado atualmente é via semente, sendo esta semeada diretamente ao solo ou em recipiente. Desta forma, é possível conseguir melhor formação do sistema radicular. Heller (1996) afirma que plantas provenientes de sementes plantadas diretamente no solo possuem crescimento mais lento que as produzidas por mudas ou estacas; no entanto, com o plantio direto da semente no solo se produzem plantas mais resistentes à seca e com maior longevidade.

O êxito esperado das plantações depende, em grande parte, da qualidade das mudas utilizadas e esta, por sua vez, está à mercê principalmente da escolha acertada do recipiente a ser utilizado, do substrato e de sua fertilização adequada, das técnicas de produção e manejo, além do tempo gasto para sua produção(Gomes, 2003).

O cultivo de plantas em substratos é uma técnica amplamente empregada na maioria dos países e apresenta várias vantagens, entre elas a de exercer função de solo fornecendo sustentação, nutriente, água e oxigênio às plantas (Fernandes \& Corá, 2001).

O tipo de recipiente e suas dimensões exercem influências sobre a qualidade e os custos de produção das mudas (Carneiro et al., 2007). A disponibilidade de nutrientes, água e a arquitetura do sistema radicular, dependem das dimensões e dos volumes dos recipientes. Para Bomfim et al. (2009), os recipientes de maior volume provêm condições semelhantes à semeadura direta no campo mas podem elevar o custo de produção.

Tendo em vista o exposto procurou-se desenvolver, neste trabalho, diversas condições para a produção de mudas de pinhão-manso em casa de vegetação. Avaliaram-se o crescimento e a qualidade das mudas submetidas a diferentes tipos e volumes de recipientes, diferentes substratos e maneiras de adubação, para a região de Piracicaba, SP, além de calcular a quantidade de água consumida da emergência ao final do período de produção das mudas.

\section{Material e MÉTOdos}

O experimento foi conduzido na área experimental do Departamento de Engenharia de Biossistemas da Escola Superior de Agricultura "Luiz de Queiroz" - USP, Piracicaba, SP, localizado a $22^{\circ} 42^{\prime} 30^{\prime \prime}$ de latitude sul, $47^{\circ} 38^{\prime} 00^{\prime \prime}$ de longitude a oeste de Greenwich e $576 \mathrm{~m}$ de altitude. O clima, segundo a classificação de Köppen, é do tipo Cwa, ou seja, clima subtropical úmido, com estiagem no inverno e chuvas no verão, com precipitação pluviométrica média de $1247 \mathrm{~mm}^{\mathrm{ano}}{ }^{-1}$, temperatura média do mês mais quente de $22^{\circ} \mathrm{C}$ e do mais frio de $18^{\circ} \mathrm{C}$, umidade relativa média de $74 \%$ e velocidade do vento média de $2,2 \mathrm{~m} \mathrm{~s}^{-1}$.

$\mathrm{O}$ experimento foi conduzido em casa de vegetação com cobertura plástica e estrutura metálica de $6,4 \mathrm{~m}$ de largura por $22,5 \mathrm{~m}$ de comprimento. A casa de vegetação possuía cortinas laterais, feitas com o mesmo filme da cobertura, cujo manejo permitia reduzir a variação de temperatura em seu interior e proteger contra chuvas e ventos. O revestimento consistia de filme de polietileno de baixa densidade (PEbd), transparente, com $0,1 \mathrm{~mm}$ de espessura e tratada contra a ação de raios ultravioletas. A estrutura experimental era provida de energia elétrica e abastecimento de água proveniente do sistema de tratamento da ESALQ/USP.

No centro da área experimental foram instalados sensores de temperatura e umidade relativa do ar (Figura 2B). Os dados foram coletados a cada minuto e a média de 15 minutos foi armazenada em “datalogger” (Campbell Scientific ${ }^{\circledR}$ ).

O delineamento experimental utilizado foi em blocos, com parcelas subsubdivididas e cinco repetições, no esquema fatorial $4 \times 3 \times 2$, com os fatores recipientes, substratos e adubações, respectivamente. As avaliações foram realizadas uma vez por semana, até a sexta semana após a germinação. 
Os recipientes constaram de tubetes de $120 \mathrm{~cm}^{3}(\mathrm{R} 1:$ medindo $38 \mathrm{~mm}$ de diâmetro interno e $140 \mathrm{~mm}$ de altura), $180 \mathrm{~cm}^{3}$ (R2: medindo $52 \mathrm{~mm}$ de diâmetro interno e $130 \mathrm{~mm}$ de altura) e de $290 \mathrm{~cm} 3$ (R3: medindo $52 \mathrm{~mm}$ de diâmetro interno e $190 \mathrm{~mm}$ de altura), além de saco plástico de $0,5 \mathrm{~L}$ (R4: medindo $170 \mathrm{~mm}$ de altura e $100 \mathrm{~mm}$ de diâmetro).

Utilizaram-se, para o fator substrato (S), o substrato comercial Plantmax $^{\circledR}(\mathrm{S} 1)$, casca de pinus (S2) e fibra de coco (S3), escolhidos por apresentarem características favoráveis à produção de mudas em geral, além de diferentes características, que podem ser visualizadas na Tabela 1 .

As adubações realizadas constavam da mesma dose de nutriente aplicada, porém com fontes diferentes: adubo de liberação lenta (A1) e adubo convencional (A2). A aplicação com adubo de liberação lenta ocorreu antes da semeadura. $\mathrm{O}$ fertilizante utilizado foi o Osmocote ${ }^{\circledR} 14-14-14$ com a dose de 5 $\mathrm{g} \mathrm{L}^{-1}$ de substrato, recomendada pelo fabricante. Aplicou-se o adubo convencional de forma parcelada, em que a quantidade de nutrientes aplicados era equivalente ao tratamento A1 $\left(\right.$ Osmocote ${ }^{\circledR}$ ) dividida em três, cuja primeira aplicação ocorreu na terceira semana, a segunda na quarta semana e a última na quinta semana após a emergência. Os adubos utilizados foram: $\left(\mathrm{NH}_{4}\right)_{2} \mathrm{SO}_{4}, \mathrm{KH}_{2} \mathrm{PO}_{4}$ e $\mathrm{K}_{2} \mathrm{SO}_{4}$ e as quantidades acumuladas podem ser verificadas na Tabela 2 .

No dia anterior ao enchimento dos recipientes os substratos foram umedecidos e, no caso dos tratamentos com adubação via Osmocote ${ }^{\circledR}$, homogeneizados com o adubo. Os recipientes foram preenchidos com os substratos e, antes da semeadura, dia 19 de maio de 2009, realizou-se a primeira irrigação, deixandoos saturados.

A quantidade de água que saiu do sistema por evaporação da superfície exposta, pela eventual drenagem do recipiente e por transpiração das mudas, foi calculada diariamente por diferença de pesagem, pela pesagem do recipiente efetuada antes de cada irrigação, com auxílio de uma balança de precisão de $0,01 \mathrm{~g}$.

Como valor de referência calibrou-se a massa dos recipientes na "capacidade de recipiente", ou seja, o equivalente à capacidade de campo em recipientes; para isto, os mesmos foram irrigados e após determinado tempo, quando a drenagem natural cessou, foram pesados. Escolheram-se os recipientes selecionados para esta determinação de acordo com a distribuição dos blocos, sendo coletadas amostras de todos os blocos.

O intervalo de tempo entre a semeadura e a emergência das plântulas não foi contabilizado por medida de precaução quanto ao efeito do umedecimento natural do substrato durante as irrigações; este tempo foi definido visando-se à estabilização da massa do recipiente (substrato) quando o mesmo estivesse na capacidade de recipiente. Mesmo assim, após a primeira semana de pesagem as massas dos recipientes foram submetidas a uma nova calibração mantendo-se este novo valor como referência para as pesagens.

Outro ajuste foi efetuado na massa referência dos recipientes visando-se, desta vez, minimizar o erro da matéria verde incrementada pelo crescimento da muda. A média da matéria verde dos tratamentos coletada na semana antecedente foi somada ao valor referência, ou seja, a cada sete dias de pesagem a matéria verde incrementada pelo crescimento da muda naquela semana, era acrescida no valor referência para as pesagens da próxima semana.

Os substratos foram umedecidos duas vezes ao dia até os primeiros dias da emergência; após isto, os mesmos foram mantidos próximos à capacidade de recipiente sendo que o intervalo de irrigação máximo não ultrapassou um dia.

A partir da data de início da emergência (nove dias após a semeadura) foram feitas, semanalmente, as seguintes determinações:

- Altura das plantas (ALT): Foi considerada como a distância entre o nível do substrato até a inserção da última folha, com o auxílio de uma fita métrica.

Tabela 1. Características e quantidade de nutrientes dos substratos utilizados antes da implantação do experimento

\begin{tabular}{|c|c|c|c|c|c|c|c|c|c|c|c|c|}
\hline \multirow[b]{2}{*}{ Substrato } & \multicolumn{6}{|c|}{ Características } & \multicolumn{6}{|c|}{ Nutrientes $\left(\mathrm{g} \mathrm{g} \mathrm{g}^{-1}\right)$} \\
\hline & $\begin{array}{l}\text { EOA } \\
(\%)\end{array}$ & $\begin{array}{c}\text { EPH20 } \\
(\%)\end{array}$ & $\mathrm{pH}$ & $\begin{array}{c}\text { DS } \\
\left(\mathrm{g} \mathrm{cm}^{-3}\right)\end{array}$ & $\begin{array}{l}\text { MO tot } \\
(\%)\end{array}$ & $\mathrm{C} / \mathrm{N}$ & N & $\mathbf{P}$ & K & $\mathrm{Ca}$ & Mg & $\mathbf{S}$ \\
\hline Plantmax ${ }^{\circledR}$ & 18,63 & 16,78 & 5,7 & 0,51 & 25,42 & $41 / 1$ & 0,42 & 0,31 & 0,12 & 0,52 & 1,15 & 0,16 \\
\hline Casca de Pinus & 18,84 & 12,12 & 5,6 & 0,46 & 31,35 & $31 / 1$ & 0,59 & 0,39 & 0,12 & 0,77 & 0,57 & 0,12 \\
\hline Fibra de coco & 25,01 & 1,68 & 6,0 & 0,29 & 19,89 & $48 / 1$ & 0,23 & 0,17 & 0,35 & 0,24 & 0,08 & 0,08 \\
\hline
\end{tabular}

EOA - espaço ocupado com ar; EPH2O - espaço ocupado com água; DS - densidade do substrato; MO tot - matéria orgânica total e C/N - relação carbono nitrogênio total

Tabela 2. Adubose quantidade acumulada de adubo aplicados nos tratamentos em g planta-1

\begin{tabular}{|c|c|c|c|c|c|c|c|c|c|c|}
\hline \multirow{2}{*}{ Tratamento* } & \multicolumn{3}{|c|}{$\left(\mathrm{NH}_{4}\right)_{2} \mathrm{SO}_{4}{ }^{1}$} & \multicolumn{3}{|c|}{$\mathrm{KH}_{2} \mathrm{PO}_{4}{ }^{1}$} & \multicolumn{3}{|c|}{$\mathrm{K}_{2} \mathrm{SO}_{4}{ }^{1}$} & \multirow{2}{*}{$\begin{array}{c}\text { OSMOCOTE }^{\circledR} \\
14-14-14\end{array}$} \\
\hline & 3 & 4 & 5 & 3 & 4 & 5 & 3 & 4 & 5 & \\
\hline T1, T3 e T5 & - & - & - & - & - & - & - & - & - & 0,084 \\
\hline T2, T4 e T6 & 0,132 & 0,198 & 0,396 & 0,055 & 0,082 & 0,164 & 0,184 & 0,276 & 0,552 & - \\
\hline T7, Т9 e T11 & - & - & - & - & - & - & - & - & - & 0,126 \\
\hline T8, T10 e T12 & 0,198 & 0,297 & 0,594 & 0,082 & 0,124 & 0,247 & 0,028 & 0,041 & 0,083 & - \\
\hline T13, T15 е T17 & - & - & - & - & - & - & - & - & - & 0,203 \\
\hline T14, T16 e T18 & 0,319 & 0,4785 & 0,957 & 0,132 & 0,199 & 0,397 & 0,044 & 0,066 & 0,133 & - \\
\hline T19, T21 e T23 & - & - & - & - & - & - & - & - & - & 0,350 \\
\hline $\mathrm{T} 20, \mathrm{~T} 22$ e T24 & 0,550 & 0,825 & 1,650 & 0,228 & 0,343 & 0,685 & 0,077 & 0,115 & 0,230 & - \\
\hline
\end{tabular}

"T1 - R1, S1, A1; T2 - R1, S1, A2; T3 - R1, S2, A1; T4 - R1, S2, A2; T5 - R1, S3, A1; T6 - R1, S3, A2; T7 - R2, S1, A1; T8 - R2, S1, A1; T9 - R2, S2, A1; T10 - R2, S2, A2; T11 - R2, S3, A1; T12 - R2, S3, A2; - T13 - R3, S1, A1;T14 - R3, S1, A2; - T15 - R3, S2, A1; T16 - R3, S2, A2;T17 - R3, S3, A1; T18 - R3, S3, A2; T19- R4, S1, A1; T20 - R4, S1, A2; T21 - R4, S2, A1; T22 - R4, S2, A2; T23 - R4, S3, A1; T24 - R4, S3, A2; R1 - Recipientes de 120 mm, R2 - 180 mm, R3 - 190 mm de altura; S1 - Substrato comercial Platmax, S2 - Casca de pinus, S3 - Fibra de coco; A1 - Adubo de liberação lenta, A2 - Adubo convencional

${ }^{1}$ Aplicada 3, 4 e 5 semanas após emergência

${ }^{2}$ Aplicada antes da semeadura 
- Diâmetro do colo ou coleto (DIAM): Medido a aproximadamente $1 \mathrm{~cm}$ do nível do substrato com paquímetro $\operatorname{digital}\left(\right.$ Starrett $\left.^{\circledR}\right)$.

$\mathrm{Na}$ coleta final, isto é, na sexta semana, os parâmetros seguintes foram avaliados:

- Comprimento do sistema radicular (CRAIZ): Padronizouse a medida da distância do início do sistema radicular até o comprimento máximo, quando a raiz principal era bem desenvolvida ou a média dos maiores comprimentos, quando a raiz principal não era bem desenvolvida.

- Massa de matéria verde total (MVTOT): As mudas foram retiradas dos recipientes (Figuras $1 \mathrm{~A}$ e B) e as partes aérea (Figura 1C) e radicular, separadas. As raízes foram limpadas com auxílio de pincel e o substrato disposto em peneira de 2 $\mathrm{mm}$ de malha, na qual as radicelas foram coletadas (Figura 1D). Realizou-se a determinação da massa com balança digital com precisão de $\pm 0,01 \mathrm{~g}$.
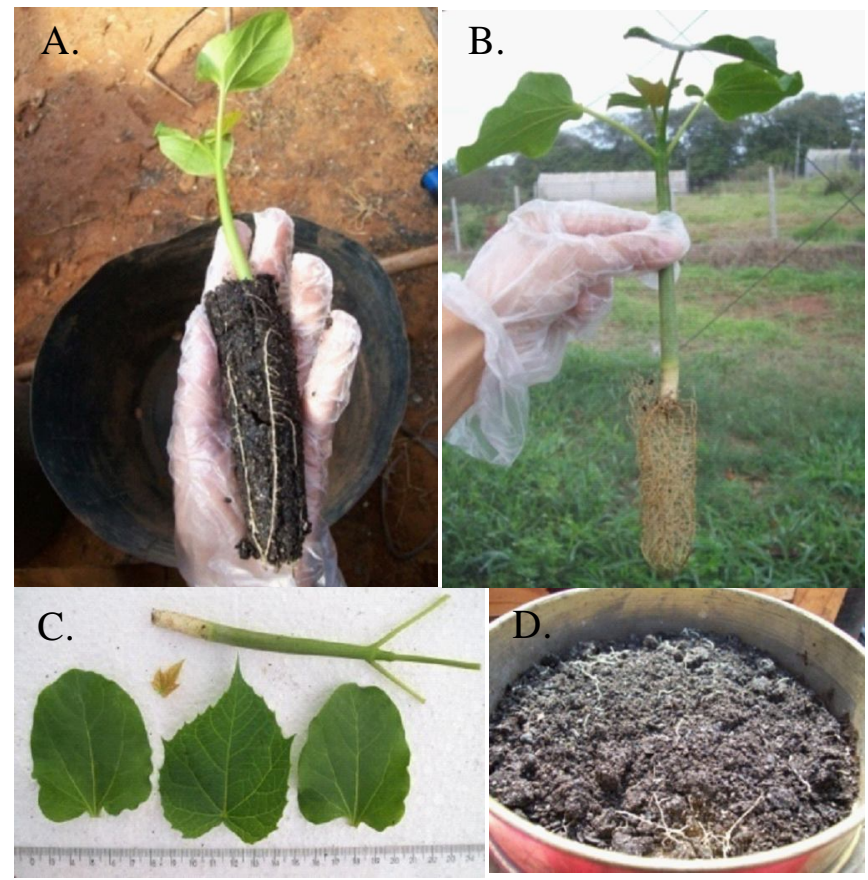

Figura 1. Retirada da muda do recipiente $(A)$, muda preparada para pesagem (B), matéria verde da parte aérea (C) e raízes dispostas na peneira para coleta (D)

- Massa de matéria seca total (MSTOT): Após a mensuração da massa fresca o material foi encaminhado para estufa com ventilação forçada a $65^{\circ} \mathrm{C}$, durante $72 \mathrm{~h}$. O material seco da parte aérea e do sistema radicular foi pesado novamente.

- Índice de qualidade Dickson (IQD): Determinado por meio da Eq. (1).

$$
\mathrm{IQD}=\frac{\mathrm{MSTOT}}{\mathrm{RAD}+\mathrm{RMS}}
$$

em que:

IQD - índice de qualidade de Dickson

MSTOT - massa seca total, $g$

RAD - razão altura-diâmetro, $\mathrm{cm} \mathrm{mm}^{-1}$
RMS - razão de massa seca da parte aérea pela raiz, adimensional

Com base nos dados obtidos em cada avaliação estimaramse algumas características de crescimento das mudas, relacionadas abaixo.

- Taxa de crescimento absoluto caulinar (TCAC): Obtida pela Eq. (2), expressa em $\mathrm{cm} \mathrm{d}^{-1}$.

$$
\mathrm{TCAC}=\frac{\mathrm{L} 2-\mathrm{L} 1}{\mathrm{t} 2-\mathrm{t} 1}
$$

donde:

L1 - Medida da altura da planta no tempo t1, cm

L2 - Medida da altura da planta no tempo 2 , cm

$\mathrm{t} 2$ - $\mathrm{t} 1$ - Intervalo de tempo entre as coletas, dias

- Taxa de crescimento absoluto em espessura caulinar (TCAEC): Calculada pela Eq. (3) e expressa em $\mathrm{cm} \mathrm{d}^{-1}$.

$$
\mathrm{TCAEC}=\frac{\mathrm{D} 2-\mathrm{D} 1}{\mathrm{t} 2-\mathrm{t} 1}
$$

sendo:

D1 - Diâmetro caulinar medido no tempo t1, cm

D2 - Diâmetro caulinar medido no tempo t2, cm

- Taxa de crescimento absoluto em massa fresca epígea (TCAMFE): Fornece a estimativa do aumento de tamanho do fitossistema $\left(\mathrm{cm}^{3} \mathrm{~d}^{-1}\right)$, expressa pela Eq. (4).

$$
\mathrm{TCAMFE}=\frac{\mathrm{L} 2 \times \mathrm{D} 2^{2}-\mathrm{L} 1 \times \mathrm{D} 1^{2}}{\mathrm{t} 2-\mathrm{t} 1}
$$

\section{RESULTADOS E DISCUSSÃO}

A temperatura média do ar no interior da casa de vegetação variou entre 13,2 e $22,8^{\circ} \mathrm{C}$ (Figura $2 \mathrm{~A}$ ). A umidade relativa média foi de $75 \%$ variando entre 61,3 e $88,8 \%$ (Figura 2B). A máxima temperatura registrada ocorreu no dia 31 de maio, marcando $40{ }^{\circ} \mathrm{C}$, e a mínima ocorreu na madrugada do dia 04 de junho, registrando por volta de $2^{\circ} \mathrm{C}$. Apesar da ocorrência de baixas temperaturas na casa de vegetação, elas não provocaram danos visíveis nas folhas das mudas. Andrade et al. (2007) notaram danos provocados por baixas temperaturas apenas em mudas submetidas a temperaturas inferiores a $-2^{\circ} \mathrm{C}$.

A quantidade de água consumida do início da emergência das mudas até o seu estágio final para cada recipiente, está apresentada na Figura 3; pode-se notar claramente as diferenças entre os recipientes e os substratos utilizados. Analisando o fator recipiente tem-se que o que proporcionou o menor consumo de água para produzir uma muda, foi o tubete de 120 $\mathrm{cm}^{3}, 0,58 \mathrm{~L}$, seguido do tubete de $180 \mathrm{~cm}^{3}$ com consumo de 0,75 $\mathrm{L}$, aproximando-se bastante do saco plástico de $500 \mathrm{~cm}^{3} \mathrm{com}$ consumo de $0,81 \mathrm{~L}$; já o maior consumo foi com o tubete de 290 
A.
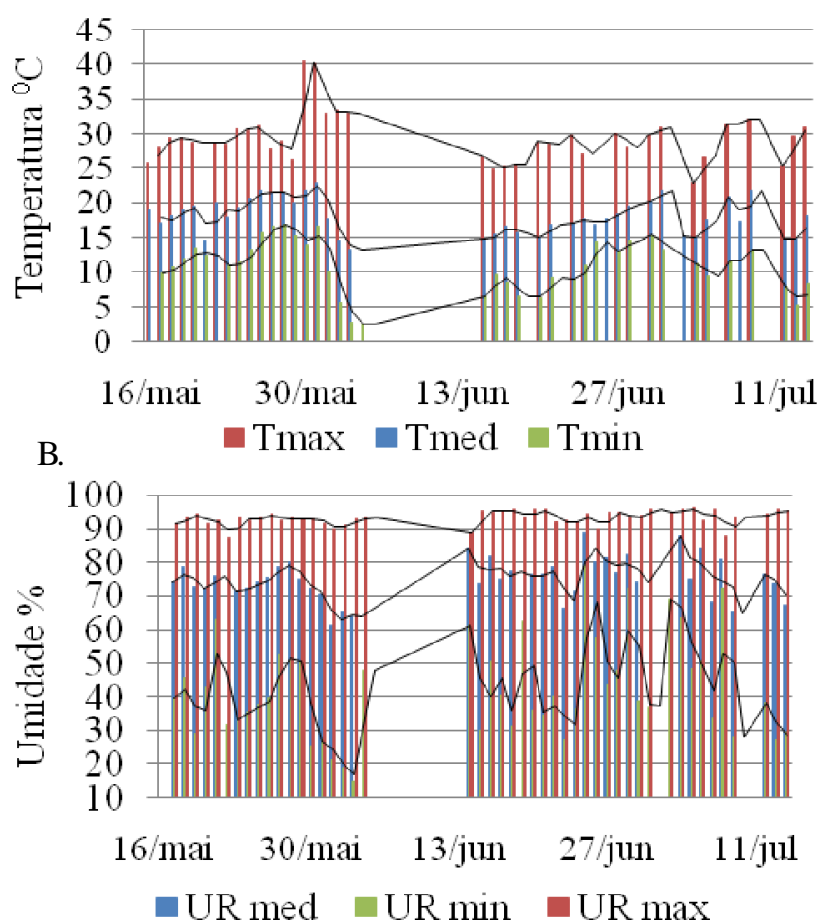

Figura 2. Variação da temperatura mínima, média e máxima do ar (A) e umidade relativa mínima, máxima e média do ar (B) no interior da casa de vegetação

$\mathrm{cm}^{3}, 0,99 \mathrm{~L}$. Na média de consumo avaliando o fator substrato, o substrato comercial Plantmax ${ }^{\circledR}(\mathrm{S} 1)$ teve o maior valor seguido do substrato casca de pinus (S2) e fibra de coco (S3), sendo $1,14,0,75$ e $0,46 \mathrm{~L}$, respectivamente.

Percebe-se, na combinação dos dois fatores que, independentemente do recipiente utilizado, o substrato $\mathrm{S} 1$ apresentou os maiores consumos, seguido dos substratos S2 e S3, sendo que a junção do substrato $S 1$ com o recipiente R3 foi o tratamento que proporcionou o maior consumo. É possível notar, também, que para S1 e S2 a quantidade de água consumida para produzir uma muda de pinhão-manso aumenta com o aumento do volume dos tubetes e o consumo do saco plástico se assemelhou ao do tubete de $180 \mathrm{~cm}^{3}$; já para S3, a quantidade de água consumida aumenta com o aumento do volume do recipiente.

O consumo médio diário variou entre 8,1 a $34,1 \mathrm{~mL}$ para R1S3 e R3S1, respectivamente. O consumo máximo encontrado foi de $69 \mathrm{~mL}$ nos dias finais de avaliação para R3S1 seguido do R4S1 com valor de $64 \mathrm{~mL}$; já os mínimos foram encontrados nos dias iniciais após a emergência sendo, para R1S3 e R3S3, com valores de 1,16 e 1,76 mL.

Apesar do recipiente $\mathrm{R} 4$ ter o maior volume, o recipiente R3 foi o que proporcionou os maiores consumos de água. De acordo com Leles et al. (2006) os tubetes proporcionam fluxo preferencial para o percurso da água para o furo no fundo do recipiente em virtude das ranhuras da parede; por este motivo é provável que o maior consumo pelo tubete de $290 \mathrm{~cm}^{3}$ (R3) tenha sido proporcionado pela influência da maior drenagem ocorrida no decorrer do dia, quando comparado com o saco plástico; outra observação quanto ao fato do recipiente R3 ter apresentado o maior consumo é que as plantas nele conduzidas
A.
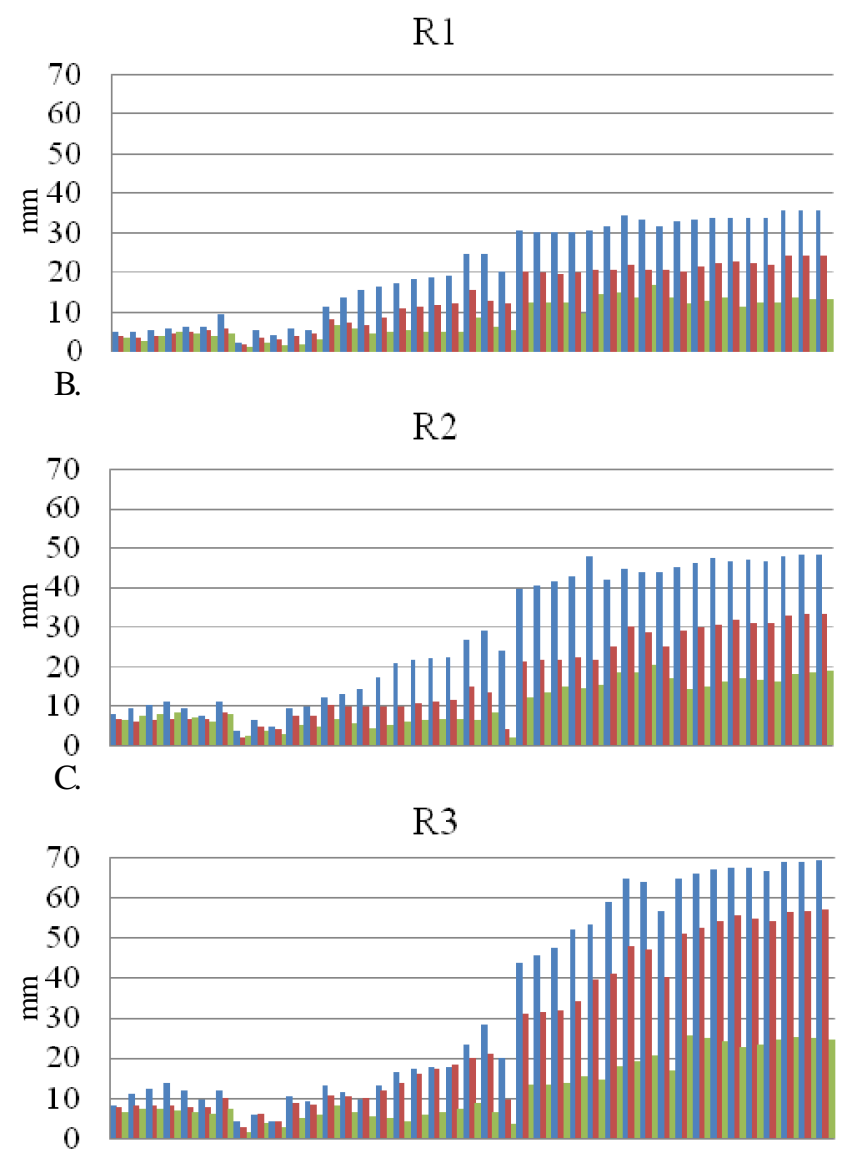

D.

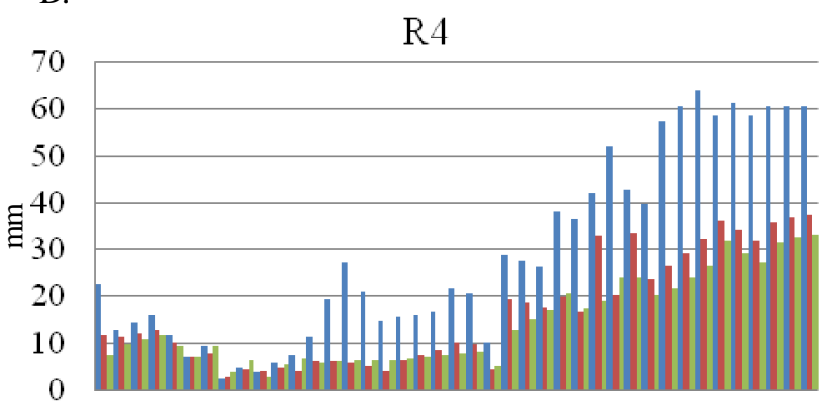

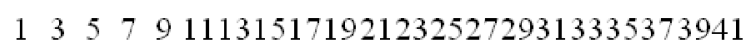

Dias após emergência

$\square$ S1 $\square$ S2 $\square 3$

Figura 3. Total de água consumida diariamente ao longo do experimento a partir de emergência das mudas, para os substratos em cada recipiente, em mililitros

apresentaram melhor desenvolvimento com os substratos S1 e S2, ocasionando o maior consumo de água por transpiração das plantas.

As taxas de crescimento absoluto caulinar em espessura caulinar e de massa fresca epígea, para as adubações ao longo das semanas avaliadas, estão apresentadas na Tabela 3, iniciando-se na semana 2 , que equivale ao crescimento ocorrido da primeira à segunda semana de coleta de dados. Observa-se diferença estatística entre as adubações na semana 3 para as taxas de crescimento avaliadas, com a adubação A1 proporcionando os melhores resultados; na semana 4 a TCAC e a TCAMFE apresentaram diferenças estatísticas para a 
adubação, com a adubação A1 com as maiores médias; para a semana 5, a adubação A1 indicou taxas de crescimento superiores às médias da adubação A2 e na última semana as diferenças estatísticas ocorreram para TCAC e TCAMFE, novamente $\mathrm{A} 1 \mathrm{com}$ as maiores taxas.

Tabela 3. Médias, para o fator adubação, da taxa de crescimento absoluto caulinar (TCAC) $\mathrm{cm} \mathrm{d}^{-1}$, taxa de crescimento absoluto em espessura caulinar (TCAEC) $\mathrm{cm}$ $\mathrm{d}^{-1}$, taxa de crescimento absoluto de massa fresca epígea (TCAM FE) $\mathrm{cm}^{3} \mathrm{~d}^{-1}$

\begin{tabular}{ccccc}
\hline Período & Adubação $^{*}$ & TCAC & TCAEC & TCAMFE \\
\multirow{2}{*}{ Semana 2 } & $\mathrm{A} 1$ & $0,141 \mathrm{~A}$ & $0,009 \mathrm{~A}$ & $0,143 \mathrm{~A}$ \\
& $\mathrm{~A} 2$ & $0,119 \mathrm{~A}$ & $0,009 \mathrm{~A}$ & $0,132 \mathrm{~A}$ \\
\hline \multirow{2}{*}{ Semana 3 } & $\mathrm{A} 1$ & $0,059 \mathrm{~A}$ & $0,008 \mathrm{~A}$ & $0,128 \mathrm{~A}$ \\
& $\mathrm{~A} 2$ & $0,042 \mathrm{~B}$ & $0,006 \mathrm{~B}$ & $0,085 \mathrm{~B}$ \\
\hline \multirow{2}{*}{ Semana 4 } & $\mathrm{A} 1$ & $0,116 \mathrm{~A}$ & $0,009 \mathrm{~A}$ & $0,191 \mathrm{~A}$ \\
& $\mathrm{~A} 2$ & $0,048 \mathrm{~B}$ & $0,008 \mathrm{~A}$ & $0,129 \mathrm{~B}$ \\
\hline \multirow{2}{*}{ Semana 5 } & $\mathrm{A} 1$ & $0,086 \mathrm{~A}$ & $0,009 \mathrm{~A}$ & $0,216 \mathrm{~A}$ \\
& $\mathrm{~A} 2$ & $0,032 \mathrm{~B}$ & $0,007 \mathrm{~B}$ & $0,115 \mathrm{~B}$ \\
\hline \multirow{2}{*}{ Semana 6 } & $\mathrm{A} 1$ & $0,042 \mathrm{~A}$ & $0,010 \mathrm{~A}$ & $0,220 \mathrm{~A}$ \\
& $\mathrm{~A} 2$ & $0,017 \mathrm{~B}$ & $0,008 \mathrm{~A}$ & $0,128 \mathrm{~B}$ \\
\hline
\end{tabular}

Médias seguidas da mesma letra na coluna não diferem entre si a nível de $5 \%$ de probabilidade pelo teste Tukey

* A1 - Adubação de liberação lenta; A2 - Adubação convencional

Na Tabela 4 estão as taxas de crescimento absoluto para os recipientes; na semana 3, diferenças estatísticas foram observadas para todas as taxas; para TCAC o recipiente $\mathrm{R} 2$ apresentou a maior e o R4 a menor taxa; para TCAEC a maior taxa ocorreu com o uso do recipiente R3 e para TCAMFE o recipiente $\mathrm{R} 3$ também apresentou a maior taxa; a TCAEC foi a única taxa no qual houve diferença significativa na semana 5,

Tabela 4. Médias, para o fator recipiente, da taxa de crescimento absoluto caulinar (TCAC) $\mathrm{cm} \mathrm{d}^{-1}$, taxa de crescimento absoluto em espessura caulinar (TCAEC) $\mathrm{cm}$ $d^{-1}$, taxa de crescimento absoluto de massa fresca epígea (TCAM FE) $\mathrm{cm}^{3} \mathrm{~d}^{-1}$

\begin{tabular}{ccccc}
\hline Período & Recipiente $^{*}$ & TCAC & TCAEC & TCAMFE \\
& $\mathrm{R} 1$ & $0,124 \mathrm{~A}$ & $0,0087 \mathrm{~A}$ & $0,132 \mathrm{~A}$ \\
Semana 2 & $\mathrm{R} 2$ & $0,123 \mathrm{~A}$ & $0,0110 \mathrm{~A}$ & $0,148 \mathrm{~A}$ \\
& $\mathrm{R} 3$ & $0,140 \mathrm{~A}$ & $0,0094 \mathrm{~A}$ & $0,132 \mathrm{~A}$ \\
& $\mathrm{R} 4$ & $0,133 \mathrm{~A}$ & $0,0084 \mathrm{~A}$ & $0,136 \mathrm{~A}$ \\
\hline \multirow{5}{*}{ Semana 3 } & $\mathrm{R} 1$ & $0,052 \mathrm{AB}$ & $0,007 \mathrm{AB}$ & $0,108 \mathrm{AB}$ \\
& $\mathrm{R} 2$ & $0,070 \mathrm{~A}$ & $0,007 \mathrm{AB}$ & $0,114 \mathrm{AB}$ \\
& $\mathrm{R} 3$ & $0,047 \mathrm{AB}$ & $0,009 \mathrm{~A}$ & $0,130 \mathrm{~A}$ \\
& $\mathrm{R} 4$ & $0,031 \mathrm{~B}$ & $0,005 \mathrm{~B}$ & $0,071 \mathrm{~B}$ \\
\hline \multirow{5}{*}{ Semana 4 } & $\mathrm{R} 1$ & $0,072 \mathrm{~B}$ & $0,008 \mathrm{AB}$ & $0,151 \mathrm{~B}$ \\
& $\mathrm{R} 2$ & $0,079 \mathrm{AB}$ & $0,008 \mathrm{AB}$ & $0,152 \mathrm{AB}$ \\
& $\mathrm{R} 3$ & $0,112 \mathrm{~A}$ & $0,002 \mathrm{~A}$ & $0,214 \mathrm{~A}$ \\
& $\mathrm{R} 4$ & $0,062 \mathrm{~B}$ & $0,007 \mathrm{~B}$ & $0,122 \mathrm{~B}$ \\
\hline \multirow{5}{*}{ Semana 5 } & $\mathrm{R} 1$ & $0,051 \mathrm{~A}$ & $0,008 \mathrm{AB}$ & $0,147 \mathrm{~A}$ \\
& $\mathrm{R} 2$ & $0,062 \mathrm{~A}$ & $0,011 \mathrm{~A}$ & $0,208 \mathrm{~A}$ \\
& $\mathrm{R} 3$ & $0,063 \mathrm{~A}$ & $0,009 \mathrm{AB}$ & $0,185 \mathrm{~A}$ \\
& $\mathrm{R} 4$ & $0,058 \mathrm{~A}$ & $0,006 \mathrm{~B}$ & $0,120 \mathrm{~A}$ \\
\hline \multirow{5}{*}{ Semana 6 } & $\mathrm{R} 1$ & $0,017 \mathrm{~B}$ & $0,011 \mathrm{~A}$ & $0,147 \mathrm{~B}$ \\
& $\mathrm{R} 2$ & $0,027 \mathrm{AB}$ & $0,009 \mathrm{AB}$ & $0,181 \mathrm{AB}$ \\
& $\mathrm{R} 3$ & $0,046 \mathrm{~A}$ & $0,011 \mathrm{~A}$ & $0,237 \mathrm{~A}$ \\
& $\mathrm{R} 4$ & $0,027 \mathrm{AB}$ & $0,007 \mathrm{~B}$ & $0,130 \mathrm{~B}$ \\
\hline
\end{tabular}

Médias seguidas da mesma letra na coluna não diferem entre si ao nível de $5 \%$ de probabilidade pelo teste Tukey

* R1 - Recipiente de 120 mm, R2 - 180 mm, R3 - 190 mm de altura em que o recipiente R2 superou R4; já na sexta semana as três taxas avaliadas apresentaram diferenças estatísticas, para TCAC, o recipiente $\mathrm{R} 3$ foi o que apresentou maior média que $\mathrm{R} 1$ e R4, para TCAEC os recipientes R1 e R2 superaram R4 e para TCAMFE o R1 e R4 foram inferiores ao tratamento R3.

Analisando os substratos nota-se, na Tabela 5, que para a semana 2 o substrato $\mathrm{S} 1$ apresentou os maiores valores de TCAEC e TCAMFE, diferindo estatisticamente dos demais substratos; na terceira semana os substratos S1 e S2 indicaram as maiores médias para TCAC e o substrato $S 1$ foi superior aos demais para os parâmetros TCAEC e TCAMFE; para o parâmetro TCAMFE, $\mathrm{S} 1$ foi superior também nas quarta e quinta semanas, porém na sexta semana o substrato S2 não teve diferença do S1; na quarta semana S1 e S2 obtiveram os maiores valores não se diferenciando entre si para TCAC e o substrato S1 superou estatisticamente os demais para, TCAEC.

Tabela 5. Médias, para o fator substrato, da taxa de crescimento absoluto caulinar (TCAC) $\mathrm{cm} \mathrm{d}^{-1}$, taxa de crescimento absoluto em espessura caulinar (TCAEC) $\mathrm{cm}$ $d^{-1}$, taxa de crescimento absoluto de massa fresca epígea (TCAM FE) $\mathrm{cm}^{3} \mathrm{~d}^{-1}$

\begin{tabular}{ccccc}
\hline Período & Substrato $^{*}$ & TCAC & TCAEC & TCAMFE \\
& S1 & $0,146 \mathrm{~A}$ & $0,013 \mathrm{~A}$ & $0,181 \mathrm{~A}$ \\
Semana 2 & S2 & $0,135 \mathrm{~A}$ & $0,008 \mathrm{~B}$ & $0,118 \mathrm{~B}$ \\
& $\mathrm{~S} 3$ & $0,109 \mathrm{~A}$ & $0,008 \mathrm{~B}$ & $0,113 \mathrm{~B}$ \\
\hline \multirow{3}{*}{ Semana 3 } & $\mathrm{S} 1$ & $0,055 \mathrm{AB}$ & $0,009 \mathrm{~A}$ & $0,143 \mathrm{~A}$ \\
& $\mathrm{~S} 2$ & $0,054 \mathrm{~A}$ & $0,006 \mathrm{~B}$ & $0,096 \mathrm{~B}$ \\
& $\mathrm{~S} 3$ & $0,031 \mathrm{~B}$ & $0,006 \mathrm{~B}$ & $0,080 \mathrm{~B}$ \\
\hline \multirow{3}{*}{ Semana 4 } & $\mathrm{S} 1$ & $0,109 \mathrm{~A}$ & $0,011 \mathrm{~A}$ & $0,234 \mathrm{~A}$ \\
& $\mathrm{~S} 2$ & $0,094 \mathrm{~A}$ & $0,008 \mathrm{~B}$ & $0,150 \mathrm{~B}$ \\
& $\mathrm{~S} 3$ & $0,044 \mathrm{~B}$ & $0,006 \mathrm{~B}$ & $0,096 \mathrm{C}$ \\
\hline \multirow{3}{*}{ Semana 5 } & $\mathrm{S} 1$ & $0,067 \mathrm{~A}$ & $0,010 \mathrm{~A}$ & $0,219 \mathrm{~A}$ \\
& $\mathrm{~S} 2$ & $0,065 \mathrm{~A}$ & $0,008 \mathrm{AB}$ & $0,152 \mathrm{~B}$ \\
& $\mathrm{~S} 3$ & $0,043 \mathrm{~A}$ & $0,007 \mathrm{~B}$ & $0,125 \mathrm{~B}$ \\
\hline \multirow{2}{*}{ Semana 6 } & $\mathrm{S} 1$ & $0,030 \mathrm{~A}$ & $0,009 \mathrm{~A}$ & $0,213 \mathrm{~A}$ \\
& $\mathrm{~S} 2$ & $0,036 \mathrm{~A}$ & $0,009 \mathrm{~A}$ & $0,176 \mathrm{AB}$ \\
& $\mathrm{S3}$ & $0,020 \mathrm{~A}$ & $0,007 \mathrm{~A}$ & $0,133 \mathrm{~B}$ \\
\hline
\end{tabular}

Médias seguidas da mesma letra na coluna não diferem entre si a nível de $5 \%$ de probabilidade pelo teste Tukey

* S1 - Substrato comercial Plantmax, S2 - Casca de pinus, S3 - Fibra de coco

Apresenta-se, na Tabela 6, a interação entre recipiente e substrato para a segunda e quarta semanas de avaliação, observa-se que, na segunda semana, para TCAEC as diferenças estatísticas ocorreram na utilização da adubação $\mathrm{A} 1$, sendo o melhor resultado obtido pelo recipiente R3; para TCAMFE, quando se utilizou a adubação A1 o recipiente R3 diferiu de R4 com maiores valores e na utilização do recipiente $\mathrm{R} 3$ a adubação A1 mostrou-se superior.

$\mathrm{Na}$ quarta semana os recipientes R2 e R3 apresentaram diferenças estatísticas entre a adubação A1 e A2 para a TCAC, sendo A1 a maior média e na utilização da adubação $\mathrm{A} 1 \mathrm{o}$ recipiente R3 apresentou o melhor resultado; para TCAEC, a diferença ocorreu com a utilização da adubação A1 com R3 apresentando os melhores resultados; o recipiente $\mathrm{R} 3$ também superou os demais na adubação A1, para TCAMFE.

Observa-se, na Tabela 7, que nas três semanas quando se utilizou o substrato $\mathrm{S} 1$, a adubação A1 apresentou as maiores médias; com a utilização do substrato $\mathrm{S} 2$, a adubação $\mathrm{A} 1$ foi 
Tabela 6. Média das interações entre recipientes e substratos para taxa de crescimento caulinar (TCAC), taxa de crescimento em espessura caulinar (TCAEC) e taxa de crescimento em massa fresca epígea (TCAMFE), na segunda e quarta semanas de avaliação

\begin{tabular}{cccccc}
\hline Parâmetro & Adubação $^{*}$ & R1 & R2 & R3 & R4 \\
TCAC & $\mathrm{A} 1$ & $0,068 \mathrm{Aa}$ & $0,058 \mathrm{Aa}$ & $0,070 \mathrm{Aa}$ & $0,041 \mathrm{Aa}$ \\
$\left(\mathrm{cm} \mathrm{d}^{-1}\right)$ & $\mathrm{A} 2$ & $0,040 \mathrm{Aab}$ & $0,081 \mathrm{Aa}$ & $0,024 \mathrm{Ab}$ & $0,022 \mathrm{Ab}$ \\
TCAEC & $\mathrm{A} 1$ & $0,008 \mathrm{Aab}$ & $0,009 \mathrm{Aab}$ & $0,012 \mathrm{Aa}$ & $0,005 \mathrm{Ab}$ \\
$\left(\mathrm{cm} \mathrm{d}^{-1}\right)$ & $\mathrm{A} 2$ & $0,006 \mathrm{Aa}$ & $0,006 \mathrm{Aa}$ & $0,008 \mathrm{Aa}$ & $0,004 \mathrm{Aa}$ \\
$\mathrm{TCAMFE}^{-1}$ & $\mathrm{~A} 1$ & $0,132 \mathrm{Aab}$ & $0,121 \mathrm{Aab}$ & $0,172 \mathrm{Aa}$ & $0,083 \mathrm{Ab}$ \\
$\left(\mathrm{cm}^{3} \mathrm{~d}^{-1}\right)$ & $\mathrm{A} 2$ & $0,085 \mathrm{Aa}$ & $0,108 \mathrm{Aa}$ & $0,088 \mathrm{Ba}$ & $0,059 \mathrm{Aa}$ \\
\hline \multicolumn{7}{c}{ Semana 4 } \\
TCAC & $\mathrm{A} 1$ & $0,084 \mathrm{Aa}$ & $0,114 \mathrm{Aa}$ & $0,177 \mathrm{Ab}$ & $0,088 \mathrm{Aa}$ \\
$\left(\mathrm{cm} \mathrm{d}^{-1}\right)$ & $\mathrm{A} 2$ & $0,060 \mathrm{Aa}$ & $0,044 \mathrm{Ba}$ & $0,047 \mathrm{Ba}$ & $0,040 \mathrm{Aa}$ \\
TCAEC & $\mathrm{A} 1$ & $0,007 \mathrm{Aa}$ & $0,008 \mathrm{Aa}$ & $0,012 \mathrm{Ab}$ & $0,007 \mathrm{Aa}$ \\
$\left(\mathrm{cm} \mathrm{d}^{-1}\right)$ & $\mathrm{A} 2$ & $0,009 \mathrm{Aa}$ & $0,007 \mathrm{Aa}$ & $0,009 \mathrm{Aa}$ & $0,006 \mathrm{Aa}$ \\
$\mathrm{TCAMFE}^{2}$ & $\mathrm{~A} 1$ & $0,150 \mathrm{Aa}$ & $0,173 \mathrm{Aa}$ & $0,288 \mathrm{Ab}$ & $0,152 \mathrm{Aa}$ \\
$\left(\mathrm{cm}^{3} \mathrm{~d}^{-1}\right)$ & $\mathrm{A} 2$ & $0,152 \mathrm{Aa}$ & $0,130 \mathrm{Aa}$ & $0,139 \mathrm{Ba}$ & $0,935 \mathrm{Aa}$ \\
\hline
\end{tabular}

Médias seguidas de mesma letra maiúscula na coluna e minúscula na linha não diferem entre si a nível de $5 \%$ de probabilidade pelo teste Tukey

* A1 - Adubação de liberação lenta, A2 - Adubação convencional

superior a A2 para as quarta e quinta semanas e na utilização do substrato S3, a adubação A1 apresentou maior valor na quarta semana; na análise do fator adubação nota-se que, fixando-se A1, o substrato $\mathrm{S} 1$ apresentou as maiores médias nas semanas e se fixando A2 houve diferença somente na semana 4, em que o substrato $\mathrm{S} 2$ foi melhor que $\mathrm{S} 3$.

Tabela 7. M édias das interações entre substratos e adubações para taxa de crescimento em massa fresca epígea (TCAM FE) $\mathrm{cm}^{3} \mathrm{~d}^{-1}$ na terceira, quarta e quinta semana de avaliação

\begin{tabular}{ccccc}
\hline \multirow{2}{*}{ Período } & \multirow{2}{*}{ Adubação* } & \multicolumn{3}{c}{ Substrato } \\
\cline { 3 - 5 } \multirow{2}{*}{ Semana 3 } & S1 & S2 & S3 \\
& $\mathrm{A} 1$ & $0,188 \mathrm{Aa}$ & $0,112 \mathrm{Ab}$ & $0,081 \mathrm{Ab}$ \\
& $\mathrm{A} 2$ & $0,099 \mathrm{Ba}$ & $0,078 \mathrm{Aa}$ & $0,078 \mathrm{Aa}$ \\
\hline \multirow{2}{*}{ Semana 4 } & $\mathrm{A} 1$ & $0,159 \mathrm{Aa}$ & $0,117 \mathrm{Aab}$ & $0,072 \mathrm{Ab}$ \\
& $\mathrm{A} 2$ & $0,059 \mathrm{Bab}$ & $0,071 \mathrm{Ba}$ & $0,015 \mathrm{Bb}$ \\
\hline \multirow{2}{*}{ Semana 5 } & $\mathrm{A} 1$ & $0,297 \mathrm{Aa}$ & $0,201 \mathrm{Ab}$ & $0,149 \mathrm{Ab}$ \\
& $\mathrm{A} 2$ & $0,141 \mathrm{Ba}$ & $0,104 \mathrm{Ba}$ & $0,100 \mathrm{Aa}$ \\
\hline
\end{tabular}

Médias seguidas da mesma letra maiúscula na coluna e minúscula na linha não diferem entre si a nível de $5 \%$ de probabilidade pelo teste Tukey

* A1 - Adubação de liberação lenta, A2 - Adubação convencional

Na Figura 4 se encontram as taxas de crescimento absoluto caulinar para todos os tratamentos; nota-se que as maiores taxas ocorreram para os tratamentos T1, T7, T13 e T19 e as menores para os tratamentos T6, T12, T18 e T24.

Percebe-se que, na terceira semana, a TCAC apresentou queda em praticamente todos os tratamentos e justamente nesta semana foram registradas baixas temperaturas durante o experimento na casa de vegetação.

Na Figura 5 se acham as taxas de crescimento em espessura caulinar para todos os tratamentos, ao longo das semanas; observa-se que essa taxa apresentou semelhança quanto aos maiores valores encontrados para os tratamentos T1, T7, T13 e T19, referentes à adubação A1, com a utilização do substrato $\mathrm{S} 1$; quanto ao grupo de recipientes a maiores taxas podem ser visualizadas no recipiente R3 (T13 a T18). Nesta figura é
A.

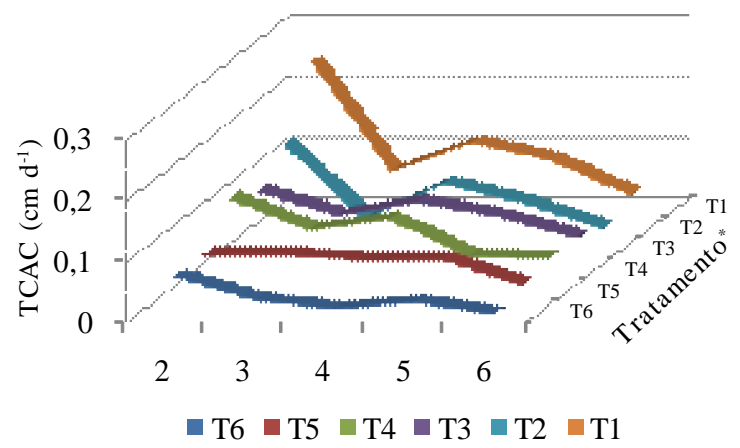

B.

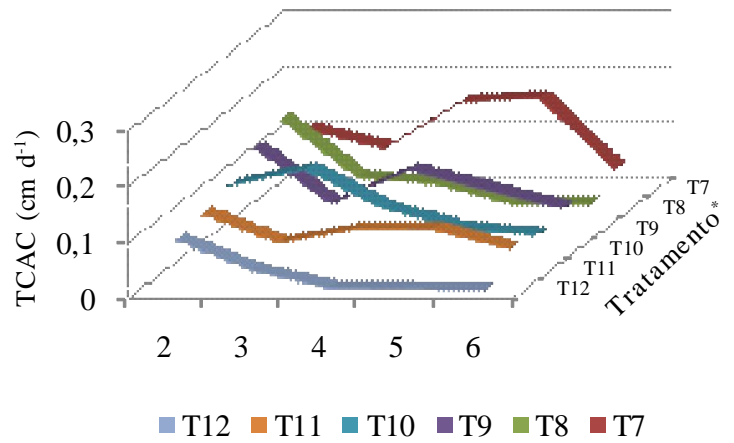

C.

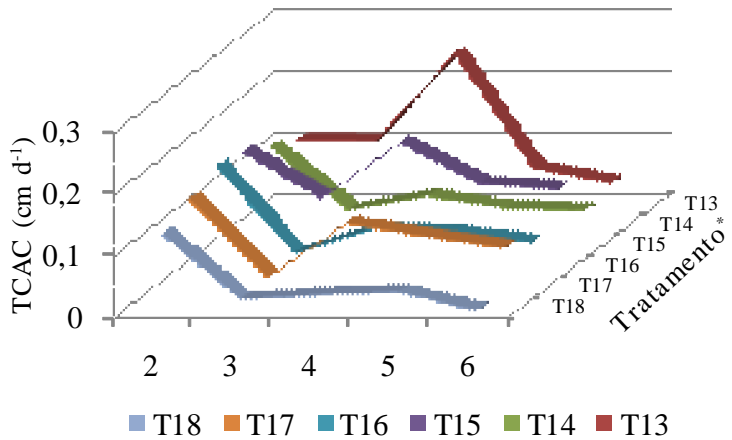

D.

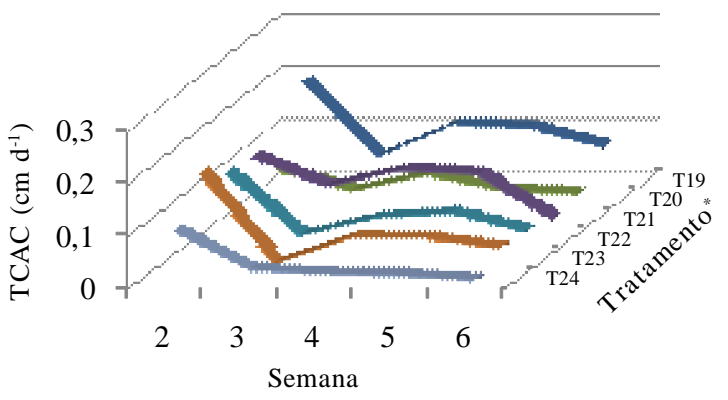

$\mathrm{T} 24 \square \mathrm{T} 23 \square \mathrm{T} 22 \square \mathrm{T} 21 \square \mathrm{T} 20 \square \mathrm{T} 19$

'T1 - R1, S1, A1; T2 - R1, S1, A2; T3 - R1, S2, A1; T4 - R1, S2, A2; T5 - R1, S3, A1; T6 - R1, S3, A2; T7 - R2, S1, A1; T8 - R2, S1, A1; T9 - R2, S2, A1; T10-R2, S2, A2; T11 - R2, S3, A1; T12 R2, S3, A2; - T13 - R3, S1, A1; T14 - R3, S1, A2; - T15 - R3, S2, A1; T16 - R3, S2, A2; T17 - R3, S3, A1; T18 - R3, S3, A2; T19 - R4, S1, A1; T20 - R4, S1, A2; T21 - R4, S2, A1; T22 - R4, S2, A2; T23 - R4, S3, A1; T24 - R4, S3, A2

Figura 4. Taxa de crescimento absoluto caulinar (TCAC) para os tratamentos T1 ao T6 (A), T7 ao T12 (B), T13 ao T18 (C) e T19 ao T24 (D ), ao longo das semanas

possível observar que a TCAEC apresentou oscilações no decorrer das semanas, porém não mostrou tendência de decréscimo, como pôde ser observado para a TCAC na Figura 4 e, sim, tendência crescente. 
A.

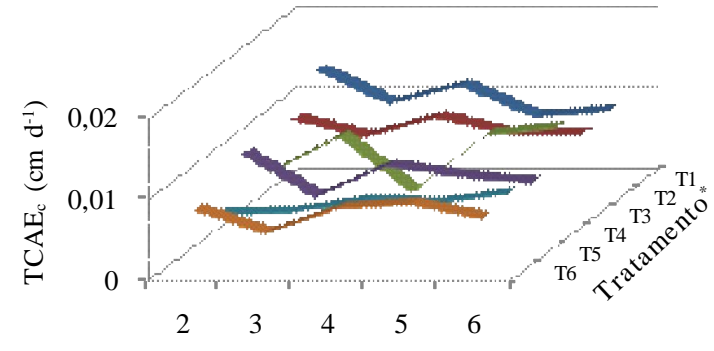

B.

T6 $-\mathrm{T} 5 \quad \mathrm{~T} 4 \quad \mathrm{~T} 3 \quad \mathrm{~T} 2 \square \mathrm{T} 1$

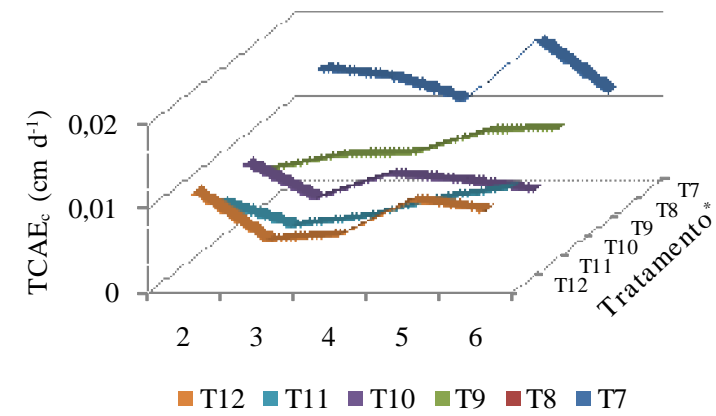

C.

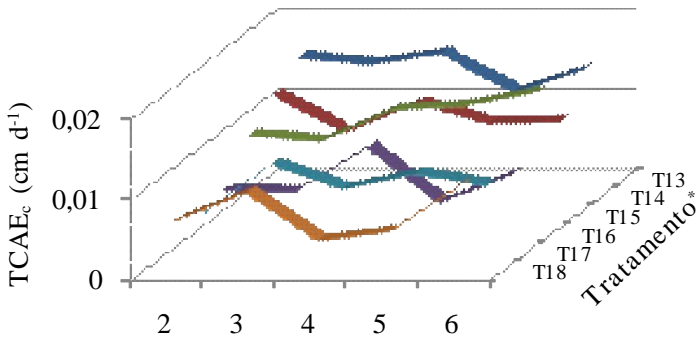

$\square \mathrm{T} 18 \square \mathrm{T} 17 \quad \mathrm{~T} 16 \quad \mathrm{~T} 15 \square \mathrm{T} 14 \quad \mathrm{~T} 13$

D.

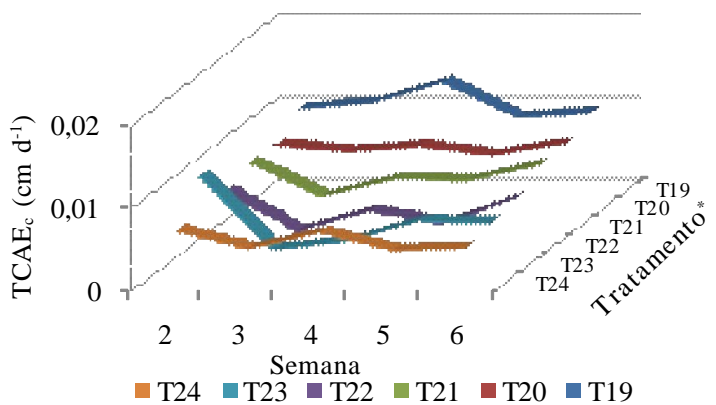

*T1 - R1, S1, A1; T2 - R1, S1, A2; T3 - R1, S2, A1; T4 - R1, S2, A2; T5 - R1, S3, A1; T6 - R1, S3, A2. T7 - R2 S1 A1: T8 - R2 S1 A1: T9 - R2 S2 A1: T10 - R2 S2 A2 T11 - R2 S3, A1:T12 R2, S3, A2; - T13 - R3, S1, A1; T14 - R3, S1, A2; - T15 - R3, S2, A1; T16 - R3, S2, A2; T17 - R3, S3, A1; T18 - R3, S3, A2; T19 - R4, S1, A1; T20 - R4, S1, A2; T21 - R4, S2, A1; T22 - R4, S2, A2; T23 - R4, S3, A1; T24 - R4, S3, A2

Figura 5. Taxa de crescimento absoluto em espessura caulinar $\left(\mathrm{TCAE}_{\mathrm{c}}\right)$ para os tratamentos T1 ao T6 (A), T7 ao T12 (B), T13 ao T18 (C) e T19 ao T24 (D), ao longo das semanas

A taxa de crescimento em massa fresca epígea (Figura 6) apresentou os maiores valores para os tratamentos que utilizaram o substrato $\mathrm{S} 1$ com a adubação A1; o mesmo foi observado para as outras taxas de crescimento. É possível notar, também na Figura 6, que os tratamentos do T1 ao T6 e do T19 ao T24, indicaram menores TCAMFE quando comparados com os demais. Esta taxa apresentou tendência crescente ao
A.

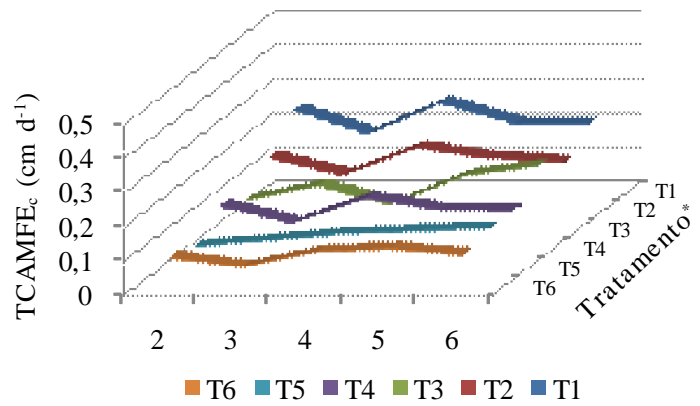

B.

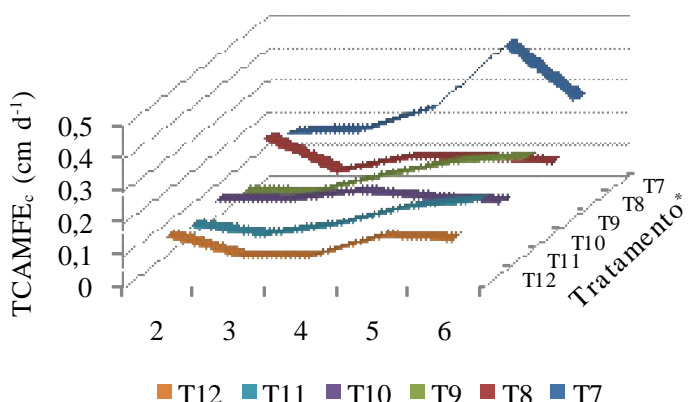

C.

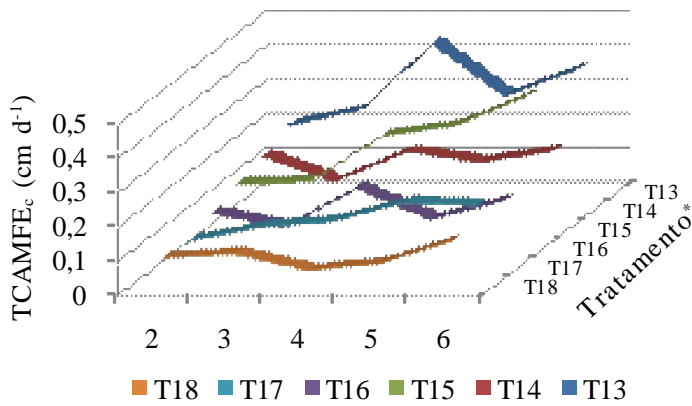

D.

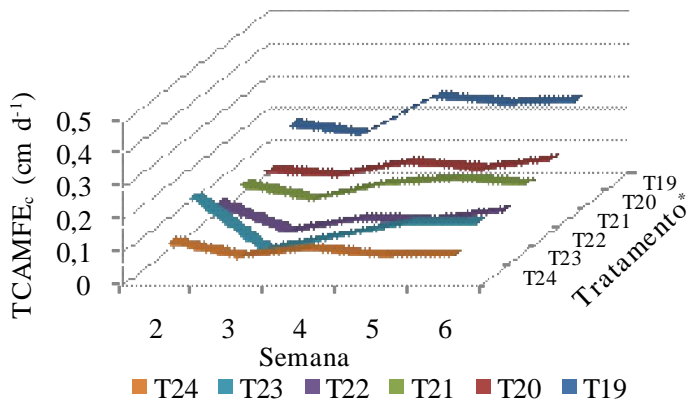

*T1 - R1, S1, A1; T2 - R1, S1, A2; T3 - R1, S2, A1; T4 - R1, S2, A2; T5 - R1, S3, A1; T6 - R1, S3, A2; T7 - R2, S1, A1; T8 - R2, S1, A1; T9 - R2, S2, A1; T10 - R2, S2, A2; T11 - R2, S3, A1;T12 R2, S3, A2; - T13 - R3, S1, A1; T14 - R3, S1, A2; - T15 - R3, S2, A1; T16-R3, S2, A2; T17 - R3, $\mathrm{S} 3, \mathrm{~A} 1 ; \mathrm{T} 18$ - R3, S3, A2; T19 - R4, S1, A1; T20 - R4, S1, A2; T21 - R4, S2, A1; T22 - R4, S2, A2; T23 - R4, S3, A1; T24 - R4, S3, A2

Figura 6. Taxa de crescimento absoluto em massa fresca epígea para os tratamentos T1 ao T6 (A), T7 ao T12 (B), T13 ao T18 (C) e T19 ao T24 (D), ao longo das semanas

longo das semanas para os tratamentos com o recipiente R2 em menor e R3 em maior proporção, R4 apresentando tendência suave; o comportamento crescente na última semana indica que, provavelmente, os tratamentos estavam em maior desenvolvimento, o que não foi observado para todos; por exemplo, o grupo de tratamentos do recipiente R1 apresentou estabilização na taxa nas últimas semanas. 
Tabela 8. M édias dos parâmetros, al tura caulinar (ALT), diâmetro caulinar (DIAM), comprimento da raiz (CRAIZ), massa verde total (MVTOT), massa seca total (MSTOT) e índice de qualidade da Dickson (IQ D), na sexta semana após a emergência

\begin{tabular}{cccccccc}
\hline Parâmetros & & ALT (cm) & DIAM (cm) & CRAIZ (cm) & MVTOT (g) & MSTOT (g) & IQD \\
\multirow{2}{*}{ Adubação } & $\mathrm{A} 1$ & $10,06 \mathrm{~A}$ & $0,881 \mathrm{~A}$ & $11,51 \mathrm{~A}$ & $13,37 \mathrm{~A}$ & $1,74 \mathrm{~A}$ & $0,25 \mathrm{~A}$ \\
& $\mathrm{~A} 2$ & $8,88 \mathrm{~B}$ & $0,830 \mathrm{~B}$ & $11,28 \mathrm{~A}$ & $9,75 \mathrm{~B}$ & $1,36 \mathrm{~B}$ & $0,16 \mathrm{~B}$ \\
\hline \multirow{4}{*}{ Recipiente } & $\mathrm{R} 1$ & $9,50 \mathrm{~A}$ & $0,848 \mathrm{AB}$ & $10,57 \mathrm{~B}$ & $10,43 \mathrm{~B}$ & $1,459 \mathrm{~B}$ & $0,17 \mathrm{~B}$ \\
& $\mathrm{R} 2$ & $9,41 \mathrm{~A}$ & $0,898 \mathrm{~A}$ & $10,05 \mathrm{~B}$ & $11,77 \mathrm{AB}$ & $1,616 \mathrm{AB}$ & $0,19 \mathrm{~B}$ \\
& $\mathrm{R} 3$ & $9,61 \mathrm{~A}$ & $0,906 \mathrm{~A}$ & $15,15 \mathrm{~A}$ & $13,14 \mathrm{~A}$ & $1,754 \mathrm{~A}$ & $0,26 \mathrm{~A}$ \\
& $\mathrm{R} 4$ & $9,38 \mathrm{~A}$ & $0,8017 \mathrm{~B}$ & $9,82 \mathrm{~B}$ & $10,88 \mathrm{~B}$ & $1,378 \mathrm{~B}$ & $0,18 \mathrm{~B}$ \\
\hline \multirow{2}{*}{ Substrato } & $\mathrm{S} 1$ & $9,88 \mathrm{~A}$ & $0,953 \mathrm{~A}$ & $12,28 \mathrm{~A}$ & $13,63 \mathrm{~A}$ & $1,90 \mathrm{~A}$ & $0,24 \mathrm{~A}$ \\
& $\mathrm{~S} 2$ & $9,46 \mathrm{AB}$ & $0,839 \mathrm{~B}$ & $12,06 \mathrm{~A}$ & $11,65 \mathrm{~B}$ & $1,54 \mathrm{~B}$ & $0,23 \mathrm{~A}$ \\
& $\mathrm{S3}$ & $9,08 \mathrm{~B}$ & $0,797 \mathrm{~B}$ & $9,86 \mathrm{~B}$ & $9,38 \mathrm{C}$ & $1,20 \mathrm{C}$ & $0,13 \mathrm{~B}$ \\
\hline
\end{tabular}

Médias seguidas da mesma letra na coluna não diferem entre si a nível de $5 \%$ de probabilidade pelo teste Tukey

* A1 - Adubo de liberação lenta, A2 - Adubo convencional; R1 - Recipientes de 120 mm, R2 - 180 mm, R3 - 190 mm de altura; S1 - Substrato comercial Platmax, S2 - Casca de pinus, S3 - Fibra de coco

Relacionando as taxas de crescimento das mudas com os parâmetros de qualidade avaliados, percebe-se que elas foram dependentes, istoé, os tratamentos que obtiveram os melhores resultados apresentaram as maiores taxas de crescimento.

Para o fator adubação (Tabela 8), o comprimento das raízes foi o único que não apresentou diferenças estatísticas; nos demais, a adubação $\mathrm{A} 1$ teve médias superiores a $\mathrm{A} 2$; no fator recipiente, o recipiente $\mathrm{R} 3$ apresentou as maiores médias de massa verde e seca total, não se diferenciando de R2 e em comprimento das raízes e no IQD, R3 se diferenciou dos demais recipientes, em maior média; com o fator substrato percebe-se que $\mathrm{S} 1$ apresentou as maiores médias para todos os parâmetros diferenciando-se estatisticamente de S2 e S3 para diâmetro caulinar, massa verde e seca total.

Na interação entre substrato e adubação (Tabela 9), quando se utilizou o substrato $\mathrm{S} 1$ somente o comprimento das raízes não se diferenciou estatisticamente entre $\mathrm{A} 1 \mathrm{e} \mathrm{A} 2$; para os demais parâmetros apresentados na Tabela 10, a adubação A1 foi a melhor; com o substrato $\mathrm{S} 2$ a massa verde das raízes apresentou maiores valores com a adubação A1; na escolha da adubação A1 o substrato $\mathrm{S} 1$ apresentou, em todos os parâmetros, os melhores resultados, não ocorrendo diferença estatística apenas de S2 para comprimento e massa verde das raízes.

Tabela 9. M édias da interação substrato e adubação para os parâmetros altura caulinar (ALT), diâmetro caulinar (DIAM ), comprimento das raízes (CRA IZ) e massa seca total (M STOT), na sexta semana após a emergência

\begin{tabular}{ccccc}
\hline \multirow{2}{*}{ Parâmetro } & \multirow{2}{*}{ Adubação* $^{*}$} & \multicolumn{3}{c}{ Substrato } \\
\cline { 3 - 5 } ALT $(\mathrm{cm})$ & $\mathrm{A} 1$ & $11,12 \mathrm{Aa}$ & $9,51 \mathrm{Ab}$ & $9,57 \mathrm{Ab}$ \\
& $\mathrm{A} 2$ & $8,64 \mathrm{Ba}$ & $9,42 \mathrm{Aa}$ & $8,59 \mathrm{Aa}$ \\
\hline \multirow{2}{*}{$\operatorname{DIAM}(\mathrm{cm})$} & $\mathrm{A} 1$ & $1,01 \mathrm{Aa}$ & $0,87 \mathrm{Ab}$ & $0,78 \mathrm{Ac}$ \\
& $\mathrm{A} 2$ & $0,90 \mathrm{Ba}$ & $0,80 \mathrm{Ab}$ & $0,80 \mathrm{Ac}$ \\
\hline \multirow{2}{*}{ CRAIZ $(\mathrm{cm})$} & $\mathrm{A} 1$ & $12,58 \mathrm{Aa}$ & $12,63 \mathrm{Aa}$ & $9,32 \mathrm{Ab}$ \\
& $\mathrm{A} 2$ & $11,98 \mathrm{Aa}$ & $11,48 \mathrm{Aa}$ & $10,39 \mathrm{Aa}$ \\
\hline \multirow{2}{*}{ MSTOT $(\mathrm{g})$} & $\mathrm{A} 1$ & $2,26 \mathrm{Aa}$ & $1,68 \mathrm{Ab}$ & $1,27 \mathrm{Ac}$ \\
& $\mathrm{A} 2$ & $1,53 \mathrm{Ba}$ & $1,40 \mathrm{Aa}$ & $1,14 \mathrm{Ab}$ \\
\hline
\end{tabular}

Médias seguidas da mesma letra maiúscula na coluna e minúscula na linha não diferem entre si ao nível de $5 \%$ de probabilidade pelo teste Tukey

* A1 - Adubo de liberação lenta, A2 - Adubo convencional

Nota-se, na Tabela 10, para a massa seca das raízes nos recipientes R1 e R3, que o substrato S3 apresentou menores valores diferenciando-se estatisticamente dos demais e, no recipiente R4, o substrato S1 superou o S3; para índice de qualidade de Dickson, os menores valores também foram encontrados para o substrato S3, apresentando diferenças estatísticas dos demais para os recipientes R1, R3 e R4. É possível perceber que o substrato S3 apresentou média do índice de qualidade de Dickson inferior a 0,2.

Tabela 10. M édias da interação recipiente e substrato para o índice de qualidade de Dickson (IQ D) e de interação recipiente e adubação para os parâmetros massa seca total (MSTOT) e comprimento das raízes (CRAIZ), na sexta semana após a germinação

\begin{tabular}{cccccc}
\hline \multirow{2}{*}{ Parâmetro } & & \multicolumn{4}{c}{ Recipiente $^{*}$} \\
\cline { 3 - 6 } & & R1 & R2 & R3 & R4 \\
& Substrato & & & & \\
\multirow{4}{*}{ IQD } & S1 & $0,213 \mathrm{Aa}$ & $0,209 \mathrm{Aa}$ & $0,288 \mathrm{Aa}$ & $0,264 \mathrm{Aa}$ \\
& $\mathrm{S} 2$ & $0,199 \mathrm{ABa}$ & $0,217 \mathrm{Aa}$ & $0,330 \mathrm{Ab}$ & $0,173 \mathrm{ABa}$ \\
& $\mathrm{S} 3$ & $0,109 \mathrm{Ba}$ & $0,141 \mathrm{Aa}$ & $0,146 \mathrm{Ba}$ & $0,111 \mathrm{Ba}$ \\
\hline \multirow{4}{*}{ MSTOT (g) } & Adubação & & & & \\
& $\mathrm{A} 1$ & $1,54 \mathrm{Aa}$ & $1,71 \mathrm{Aab}$ & $2,09 \mathrm{Ab}$ & $1,61 \mathrm{Aa}$ \\
CRAIZ (cm) & $\mathrm{A} 2$ & $1,37 \mathrm{Aa}$ & $1,52 \mathrm{Aa}$ & $1,41 \mathrm{Ba}$ & $1,14 \mathrm{Ba}$ \\
\cline { 2 - 6 } & $\mathrm{A} 1$ & $10,53 \mathrm{Aa}$ & $10,13 \mathrm{Aa}$ & $16,08 \mathrm{Ab}$ & $9,30 \mathrm{Aa}$ \\
& $\mathrm{A} 2$ & $10,62 \mathrm{Aa}$ & $9,97 \mathrm{Aa}$ & $14,22 \mathrm{Ab}$ & $10,33 \mathrm{Aa}$ \\
\hline
\end{tabular}

Médias seguidas de mesma letra maiúscula na coluna e minúscula na linha não diferem entre $\mathrm{s}$ a nível de $5 \%$ de probabilidade pelo teste Tukey

* R1 - Recipientes de $120 \mathrm{~mm}, \mathrm{R} 2$ - $180 \mathrm{~mm}, \mathrm{R} 3-190 \mathrm{~mm}$ de altura

Andrade et al. (2008) e Silva et al. (2009) estudaram a deficiência nutricional em mudas de pinhão-manso e a relacionou com a massa seca produzida, em que a produção de massa seca foi proporcional à quantidade de nutriente disponível. Analisando-se os resultados encontrados neste experimento e os relacionando com a disponibilidade de nutrientes, percebe-se que a situação que proporcionou maior disponibilidade proporcionou, também, maior massa seca.

Na maioria das análises o substrato que preponderou sobre os demais, foi o comercial Plantmax ${ }^{\circledast}$, algumas vezes não diferindo da casca de pinus; este substrato também apresentou qualidade das mudas para serem transplantadas para o campo.

Quanto aos recipientes analisados observou-se preponderância para o tubete de $290 \mathrm{~cm}^{3}$ e o saco plástico apresentou bons resultados em alguns parâmetros; já o tubete de $120 \mathrm{~cm}^{3}$ foi, na maioria dos fatores, inferior aos demais e não apresentou boa qualidade de acordo com o critério de Hunt (1990); segundo o 
autor, IQD menores que 0,2 indicam mudas não consideradas com boa qualidade final para ir para o campo e quanto maior o valor de IQD, maior também a qualidade da muda.

Para as adubações foi notável a diferença entre o adubo de liberação lenta e o adubo convencional; como o adubo de liberação lenta proporcionou mudas de boa qualidade e não apresentou diferenças visuais de falta de nutrientes, estima-se que a quantidade aplicada não foi inferior à quantidade de nutrientes necessária para o pinhão-manso, para o Plantmax ${ }^{\circledR} \mathrm{e}$ casca de pinus, porém se nota que a mesma quantidade de nutriente aplicada com fontes de adubos convencionais, apresentou mudas com qualidade inferior concluindo-se que, provavelmente, tenha ocorrido lixiviação dos nutrientes na adubação convencional já que a dose aplicada foi a mesma.

\section{CONClusões}

1. As maiores taxas de crescimento e as mudas de pinhãomanso com melhor qualidade final, foram produzidas em tubete de $290 \mathrm{~cm}^{3}$ com substrato comercial Plantmax ${ }^{\circledR}$ e adubo de liberação lenta.

2. Os tratamentos que apresentaram as maiores taxas de crescimento também indicaram melhor qualidade final das mudas na sexta semana após a emergência.

3. O substrato casca de pinus proporcionou mudas de boa qualidade enquanto as mudas produzidas com o substrato fibra de coco não mostraram qualidade final propícia para o transplantio.

4. O consumo médio de água proporcionado pela combinação recipiente/substrato que apresentou os melhores resultados na produção das mudas, ficou em torno de $1,4 \mathrm{~L}$ recipiente $^{-1}$, sendo este o maior valor entre as combinações.

\section{Agradecimentos}

Os autores agradecem ao Ministério da Ciência e Tecnologia (MCT), ao Conselho Nacional de Desenvolvimento Científico e Tecnológico (CNPq) e à Fundação de Amparo à Pesquisa do Estado de São Paulo (FAPESP), pelo apoio financeiro a esta pesquisa, através do Instituto Nacional de Ciência e Tecnologia em Engenharia da Irrigação (INCTEI) e à CAPES, pela concessão da bolsa de estudo.

\section{LITERATURA CITADA}

Achten, W. M. J.; Verchot, L.; Franken, Y. J.; Mathijs, E.; Singh, V. P.; Aerts, R. Muys, B. Jatropha bio-diesel production and use. Biomass and Bioenergy, v.32, p.1063-1084, 2009.

Andrade, G. A. A.; Caramori, P. H.; Caviglione, J. H.; Oliveira, D.; Ribeiro, A. M. A. Zoneamento agroclimático para a cultura do pinhão-manso (Jatropha curcas) no Estado do Paraná. Revista Brasileira de Agrometeorologia, v.15, p.178$183,2007$.

Andrade, T. M. Santos, H. O.; Bispo, M. C.; Santana, U. A.; Silva-Mann, R. Macronutrientes em mudas de Jatropha curcas L. In: Congresso Brasileiro de Plantas Oleaginosas, Óleos, Gorduras e Biodiesel, 5, 2008, Lavras. Anais... Lavras: UFLA, 2008. p.1468-1476.
Andréo-Souza, Y.; Pereira, A. L.;Silva, F. F. S.; Riebeiro-Reis, R. C.; Evangelista, M. R. V.; Castro, R. D.; Dantas, B. F. Efeito da salinidade na germinação de sementes e no crescimento inicial de mudas de pinhão-manso. Revista Brasileira de Sementes, v.32, p.83-92, 2010.

Bomfim, A. A. ; José, A. R. S.; Novaes, A. B.; Grisi, F. Avaliação morfológica de mudas de madeira-nova (Pterogyne nitens tull.) produzidas em tubetes e sacos plásticos e de seu desempenho no campo. Floresta, v.39, p.33-40, 2009.

Cardoso, G. D.; Alves, P. L. C. A.; Beltrão, N. E. de M.; Barreto, A. F. Uso da análise de crescimento não destrutiva com ferramenta para avaliação de cultivares. Revista de Biologia e Ciências da Terra, v.6, p.79-84, 2006.

Carneiro, J. G. A.; Barroso, D. G.; Soares, L. M. S. Crescimento de mudas em raiz nua de Pinus taeda L., sob cinco espaçamentos no viveiro e seu desempenho no campo. Revista Brasileira Agrociência, v.13, p.305-310, 2007.

Cortesão, M. Culturas tropicais: Plantas oleaginosas. Lisboa: Clássica, 1956. 231p.

Fernandes, C.; Corá, J. E. Substratos hortículas. Cultivar Hortaliças e Frutas, v.10, p.32-34, 2001.

Gomes, J. M. Crescimento de mudas de Eucalyptus grandis em diferentes tamanhos de tubetes e fertilização N-P-K. Revista Árvore, v.27, p113-127, 2003.

Heller, J. Physic nut Jatropha curcas L. Promoting the conservation and use of underutilized and neglected crops. 1. Gatersleben/ Rome: Institute of Plant Genetics and Crop Plant Research, International Plant Genetic Resources Institute, 1996. 60p.

Hunt, G. A. Effect of styroblock design and coopertreatment on morfhology of conifer seedlings. In: Target Seedlings Syposium, Meeting of the Western Forest Nursery Associations, 1990, Roseburg. Proceedings.... Fort Collins: United States Department of Agriculture, Forest Service, 1990. p.218-222.

Laviola, B. G.; Dias, L. A. S. Teor e acúmulo de nutrientes em folhas e frutos de pinhão-manso. Revista Brasileira de Ciência do Solo, v.32, p.1969-1975, 2008.

Leles, P. S. S.; Lisboa, A. L.; Oliveira Neto, S. N.; Grugiki, M. A.; Ferreira, M. A. Qualidade de mudas de quatro espécies florestais produzidas em diferentes tubetes. Floresta e Ambiente, v.13, p.69-78, 2006.

Nery, A. R.; Rodrigues, L. N.; Silva, M. B. R. da; Fernandes, P. D.; Chaves, L. H. G.; Dantas Neto, J.; Gheyi, H. R. Crescimento do pinhão-manso irrigado com águas salinas em ambiente protegido. Revista Brasileira de Engenharia Agrícola e Ambiental, v.13, p.551-558, 2009.

Silva, E. N.; Silveira, J. A. G.; Fernandes, C. R. R.; Dutra, A. T. B.; Aragão, R. M. Acúmulo de íons e crescimento de pinhãomanso sob diferentes níveis de salinidade. Revista Ciência Agronômica, v.40, p.240-246, 2009.

Silva, L. C.; Beltrão, N. E. de M.; Amorim Neto, M. S. Análise do crescimento de comunidades vegetais. Campina Grande: EMBRAPA, 2000. 18p. Circular Técnica, 34

Sunil, N.; Sivaraj, N.; Anitha, K.; Abraham, B.; Kumar, V.; Sudhir, E.; Vanja, M.; Varaprasad, K. S. Analysis of diversity and distribution of Jatropha curcas L. germplasm using Geografhic Information System (DIVA-GIS). Genetic Resources and Crop Evolution, v.56, p.115-119, 2008. 